\title{
Strain measurement during stress rupture of composite over-wrapped pressure vessel with fiber Bragg gratings sensors
}

\author{
Curtis E. Banks ${ }^{1}$, Joseph Grant ${ }^{2}$, Sam Russell ${ }^{3}$ and Shawn Arnett ${ }^{4}$ \\ ${ }^{1}$ Integrated Structure Health Monitoring and Sensors Branch \\ EV43 MSFC/NASA, Huntsville, Al 35812 \\ ${ }^{2}$ Science \& Technology Division \\ MSFC/NASA, Huntsville, A1 35812 \\ ${ }^{3}$ Nondestructive Evaluation Branch \\ EM20 MSFC/NASA, Huntsville, Al 35812 \\ ${ }^{4}$ TRI/Austin, Inc. \\ 9063 Bee Caves Rd., Austin, Texas 78733
}

\begin{abstract}
Fiber optic Bragg gratings were used to measure strain fields during Stress Rupture (SSM) test of Kevlar Composite Over-Wrapped Pressure Vessels (COPV). The sensors were embedded under the over-wrapped attached to the liner released from the Kevlar and attached to the Kevlar released from the liner. Additional sensors (foil gages and fiber bragg gratings) were surface mounted on the COPV liner.
\end{abstract}

\section{Introduction}

NASA and the aerospace industry are relying on light weight carbon composite and composite over-wrapped pressure vessels because of their strength to weight ration. These light weight structures not only reduces mass, but also the amount of propellant needed to place objects into space is reduces significantly ${ }^{1-4}$. However, Composite structures are easily damage by impacts for example, impacts caused by employees dropping tools on exposed structures, or while in transient, and more import during space flight. These serious damages, delamination or cracking of fiber and matrix can be barely visible but it can cause severe degradation of mechanical properties and load carrying capabilities of structures thus decreasing reliability and safety. In addition, Kevlar COPVs are subject to degradation over time and recertification of life expectancy is needed when they are used beyond their design life as in the case of COPVs from NASA' space shuttles ${ }^{2}$.

\section{Theoretical Background}

A FBG is a periodic array of photo-induced refractive index changes in the core of an optical fiber. These arrays are called braggs planes that are produce when two opposing laser beam interferes constructively.

When a spectrum of photons propagates through the FBG, a narrow bandwidth is reflected back while the remaining is transmitted as shown in figure 1. Figure $1 \mathrm{~b}$ shows the stages of the spectrum as it passes through the core of the fiber. The central wavelength $\lambda_{b}$ is giving in equation 1 is also called the peak wavelength. 

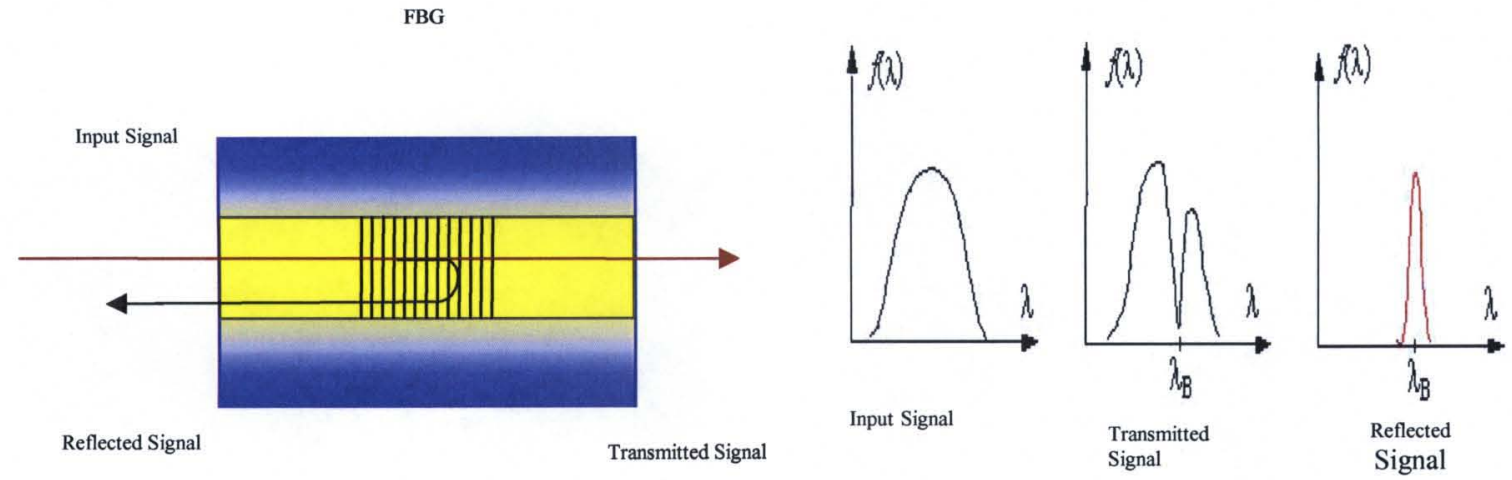

Figure 1. (a) Diagram showing how the light propagates thought the core of the fiber as a narrow bandwidth is reflected back. (b) Show a graphical representation of the intensity as a function of wavelength.

$\lambda_{\mathrm{b}}=2 \mathrm{n} \Lambda_{\mathrm{b}}(1)$

$\lambda_{b}$ is the Braggs wavelength; $\Lambda_{b}$ is the braggs planes spacing; and $n$ is the effective refractive index of the material.

The definition for strain is, $\varepsilon=1.28 *\left(\lambda-\lambda_{\mathrm{b}}\right) / \lambda_{\mathrm{b}}$

The typical wavelength shift is $\sim 1.2 \mathrm{pm} /(\mu \mathrm{m} / \mathrm{m})$ for purely strain measurements

\section{COPV Testing with embedded and surface mounted FBGs}

The COPV bottles were wrapped and tested at TRI. Two 6.3 inch were reclaimed "FBG designees" from the 100-bottle matrix. The Kevlar composite was removed from the liners and the liners were polished as shown in Figure $2 \mathrm{~A}$ and $2 \mathrm{~B}$. Previous efforts (Figures 2C and 2D) yielded inoperable FBGs as the intensity from the input source was greatly attenuated by surface roughness and accumulated micro-bending. The two 4.2inch liners used in this effort were supplied by TRI. The strands were prepared by DuPont from the same prepreg as was used to overwrap the bottles:

ATK Space Systems; TCR( $\left.{ }^{\mathrm{TM}}\right)$ Towpreg Prepreg

Kevlar 494560 (denier), Lot T10510-07, DoM 10/18/05

Resin UF3339-100, RC\% 39.6, Item ID 11808

The Bragg Grating fibers and monitoring system were procured from Micron Optics, Inc. Fibers (singlemode) were ordered with three Bragg Gratings on each with spacing that would accommodate uniform circumferential spacing on both the 4.2- and 6.3-inch bottles. The peak wavelengths used were 1530,1540 and $1550 \mathrm{~nm}$. The interrogation system was a Model sm125 which has a four channel capability. TRI provided the pc used with Microns' LabView data acquisition software.

Foil strain gages used were Vishay Micro-Measurements type CEA-00-375UW-350. Voltage applied to them was provided by a Hewlett Packard power supply. A Hewlett Packard HP-4892 data acquisition system and a LabView VI written at TRI were used to 
collect strain gage, thermocouple and pressure data. Pressure was dynamically controlled on the bottles using a Tescom ER-3000 programmable pressure controller and Model 261763-24 bypass regulator and a Hydraulics International Model 7S-DL-60 duplex pump (9000 psi). Tescom also supplied a Model 100-5000-2127, 4-20 mA pressure transmitter. In an effort to leveraged TRI/Austin, Inc. was tasked by MSFC Contract Number NNM07AB73P to evaluate Fiber Bragg Gratings (FBG) as strain sensors applied to COPVs (aka, bottles) undergoing stress and stress rupture testing. During the NNWG NDE first campaign COPV testing, FBGs were intended to be included in the stress rupture specimen matrix of 100 bottles. However, two of the four specified bottles were wound with overlapping fibers between the aluminum liner and the overwrapped Kevlar prepreg. During cure, compressive stresses (liner expansion, composite shrinkage) caused the fibers to separate where overlapped. The second pair of bottles were found to have substantial light loss along the fibers that was subsequently determined to be due to the roughness of the surface finish of the liners as received from the manufacturer (Figures 1.1 and 1.2). It is presumed that microbending of the fiber allowed light to be lost from the core, preventing the gratings from reflecting coherent light signals back to the sensor instrument.

Additional funding was therefore identified to conduct a test effort primarily focused on the evaluation of FBGs as strain sensors either embedded between the COPV liner and overwrap or bonded to the surface of the overwrap. This report will detail the results of testing two 4.2- and two 6.3-inch diameter bottles and document the performance of FBGs compared to standard foil strain gages. 

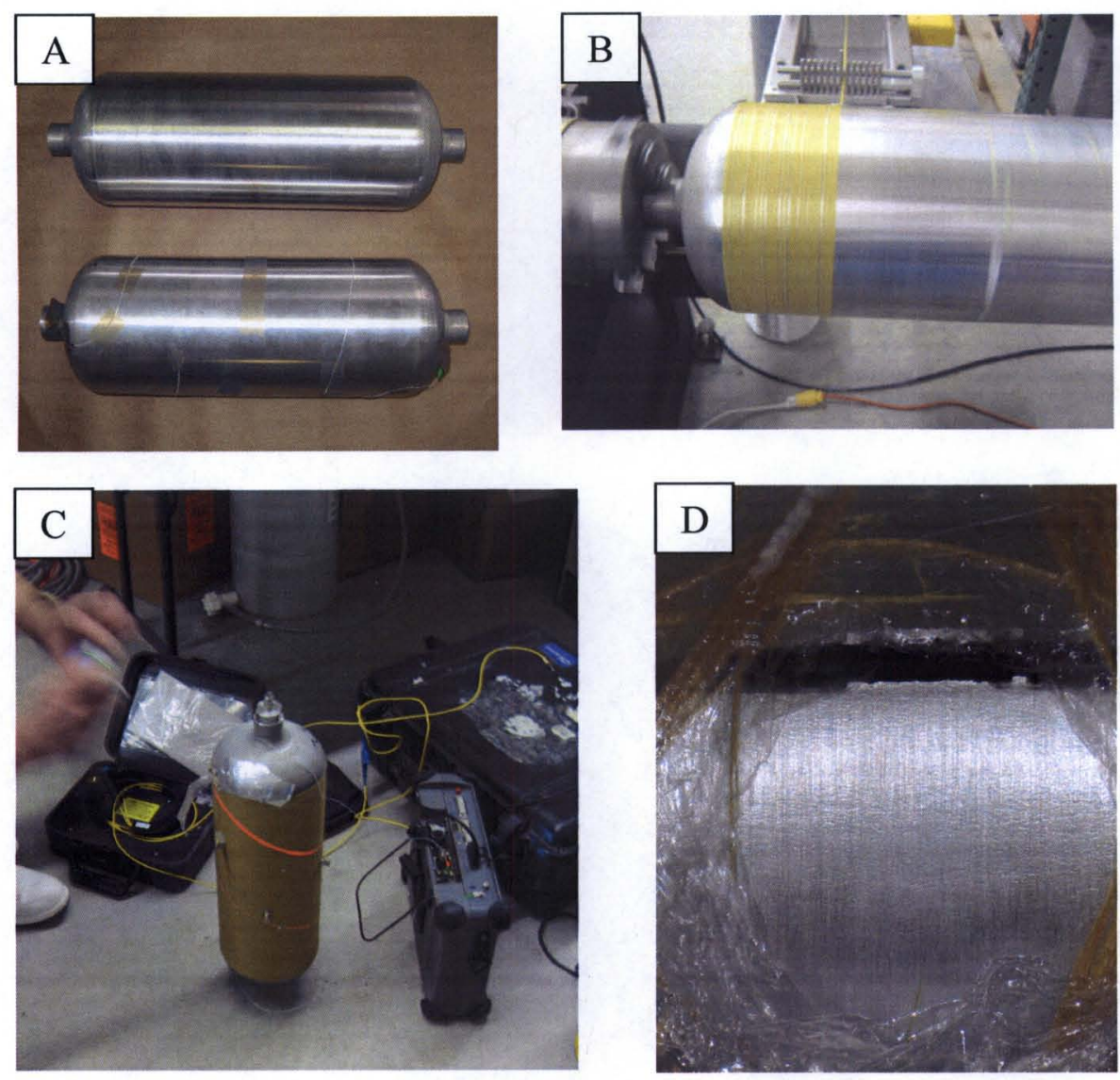

Figures 2. Photos $\mathrm{A} \& \mathrm{~B}$ show the polishing and wrapping process. Photo $\mathrm{C}$ shows the FBG being probed with laser probe. The source was greatly attenuated by the Kevlar caused by micro mending. Photo D illustrates the typical surface roughness before overwrap.

\section{COPV TESTING WITH EMBEDDED AND SURFACE MOUNTED FBGs}

Two 6.3- and two 4.2-inch diameter COPVs were tested. Each had at least one FBG on the liner and one bonded to the outer surface of the composite overwrap. Various conditions of bonding or unbonding (isolated, release agent application) were tried on the embedded sensors.

\section{Stepped Stress Method (SSM) Test on 6.3-inch COPVS}

One of the 6.3-inch bottles originally wound at MSFC with installed FBGs and subsequently reclaimed and rewound at TRI was subjected to a SSM test. One fiber's three FBG sensors were adhesively bonded to the liner with AE-10 epoxy (a standard bonding agent from Vishay Micro-Measurements for attaching strain gages). In each case the sensors were isolated from the composite overwrap with Teflon tape as a release agent. The sensor is shown in Figures 3 and 4 below. 


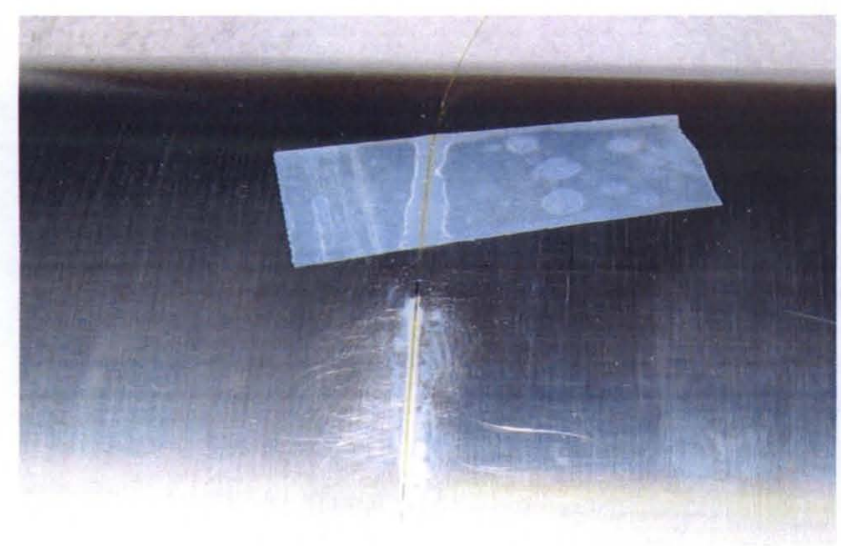

Figure 3 - FBG Sensor Bonded to Polished Liner with AE-10 Epoxy Adhesive

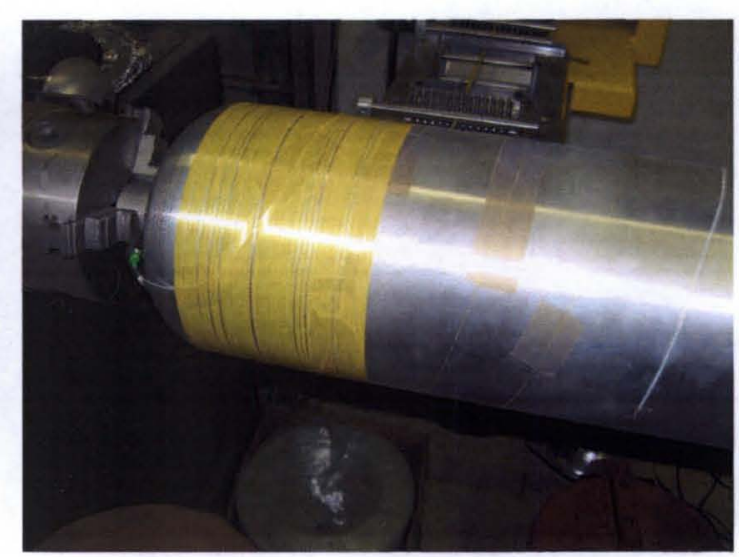

Figure 4 - ATK Prepreg Overwrapping of Liner and Embedded Fiber (Teflon Tape Used to Release Sensors from Composite)

After winding, one fiber's three FBGs were bonded to the surface of the composite and strain gages were bonded adjacent to them. AE sensors were applied to the bottle prior to pressure applications at $35,55,70$ and $80 \%$ of ultimate burst strength. Dwell times of 10,000 seconds were used for each stress level. Figures $5 \mathrm{a}$ and $5 \mathrm{~b}$ show FBG peaks for the sensors bonded to the liner. One set of curves was measured with the bottle still warm from oven curing of the AE-10 adhesive used to bond the sensor to the liner. The next were taken immediately after winding but before post-curing of the Kevlar prepreg. The last two were after post-curing, one with the light launched at the $1530 \mathrm{~nm}$ sensor and another with it launched at the $1550 \mathrm{~nm}$ sensor. (These fibers have optical connectors terminated at each end.) Micron informed us that when the light is launched to encounter the $1530 \mathrm{~nm}$ sensor first, the overall height peak-to-baseline will be larger. Not surprisingly, post-curing of the Kevlar composite results in compressive stresses being applied to the fiber that attenuate and distort the shape of the peaks. 

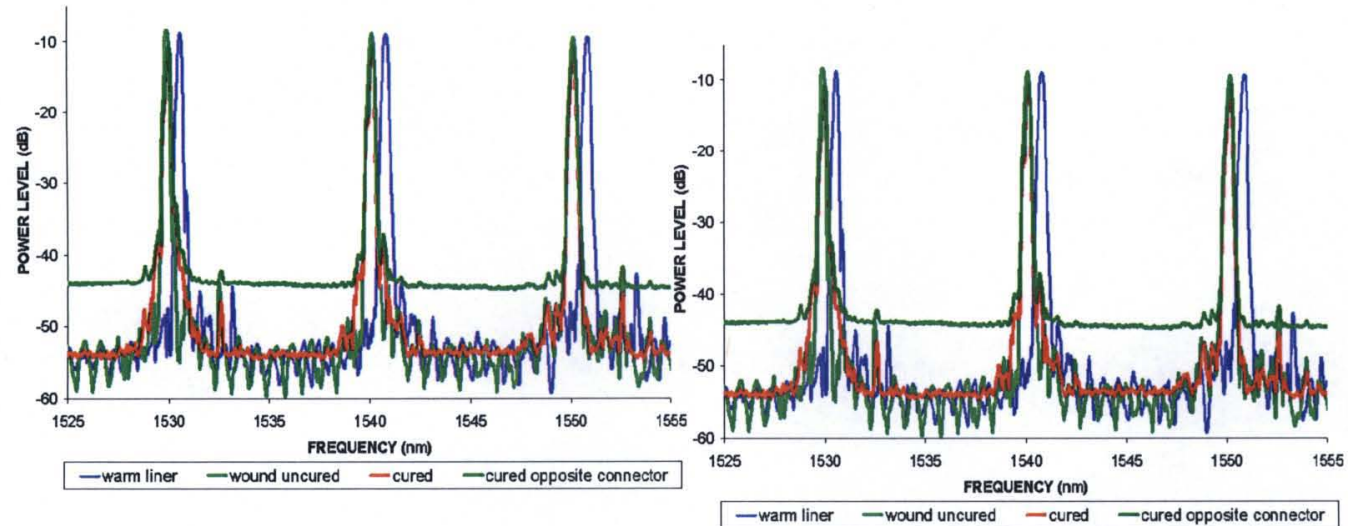

Figure 5 a) - FBG on liner under various conditions - warm liner is after postcuring sensor epoxy before winding; cured opposite connector shows effect on baseline from changing direction of light launch path. b) $1530 \mathrm{~nm}$ Peak attenuation and shifting due to added compression after cure.

Figure 6 shows the sensors data during the SSM stress rupture test. The traditional strain gag - showed in red - shows unevenness in the strain field around the circumference of the liner. Similarly the FBGs on the composite - blue or lower curves - showed the same behaviors. However, the strain fields on the liner showed in green - upper set of curvesdiffered by $1000-2000$ micro-strains. This is because the strain levels at the boundary layers is though to be higher that the levels at the surfaces.

Figure 7 took the average of the three gages and plotted them alone with the acoustic emission (AE) data - the AE data is beyond the scope of this report. But the strain levels at the liner layer interface were grater than that on the composite.

It should be noted that the power levels for the FBGs bonded to the liner were much more attenuated by pressure than were those on the outer surface of the composite overwrap. This is not surprising since attenuation is expected when the fiber is compressed. The strain gages appeared to see slightly higher strains than their adjacent FBGs.

\section{Second 6.3-Inch COPV SSM Test}

On the second of the larger liners, one FBG sensor was bonded to the liner and released from the composite and one was released from the liner and exposed to the composite, where it presumably would bond to the Kevlar prepreg during elevated temperature cure. This embedded fiber only had two sensors since it was decided to sever the fiber and isolate a single sensor (of three) to apply to the outside surface of the COPV after postcuring the Kevlar prepreg. These fibers were delivered with optical connectors on each end of the fiber, making such a separation of sensors possible. All of the FBGs initially delivered from MSFC were made by Micron Optics and had peaks at 1530, 1540 and $1550 \mathrm{~nm}$. One additional FBG was delivered just prior to this test that had a single sensor with a peak wavelength (unstrained) of $1562 \mathrm{~nm}$. Pressure levels for this test were nominally 35, 55, 65 and 85 percent of burst strength $(1585,1930,2067$ and 2423 psig, respectively). Due to attenuation of some FBG signals, the pressure was reduced during the second dwell to $1140 \mathrm{psig}$ in an attempt to reacquire peaks as a diagnostic check. 
Figure 8 shows the averaged microstrains for the FBGs and the strain gages. As seen in previous stress rupture tests, the axial strain gages (and in this case the FBG) exhibited significantly lower strains than for those mounted in the hoop direction.

The FBG released from the liner and exposed to the intentional bonding to the composite failed to be detected early in the test. It is quite possible that the uncontrolled surface of the overwrapped composite created a condition of multiaxial stresses that caused rapid attenuation of the peak signal. This condition was observed on the surface of the composite and attempts were made to provide a flat, pre-cured platform of epoxy to bond the sensor to minimize axial compressive stresses and to maximize uniaxial longitudinal stress on the fibers.

Figure 9 shows the fail vessel after stress rupture.

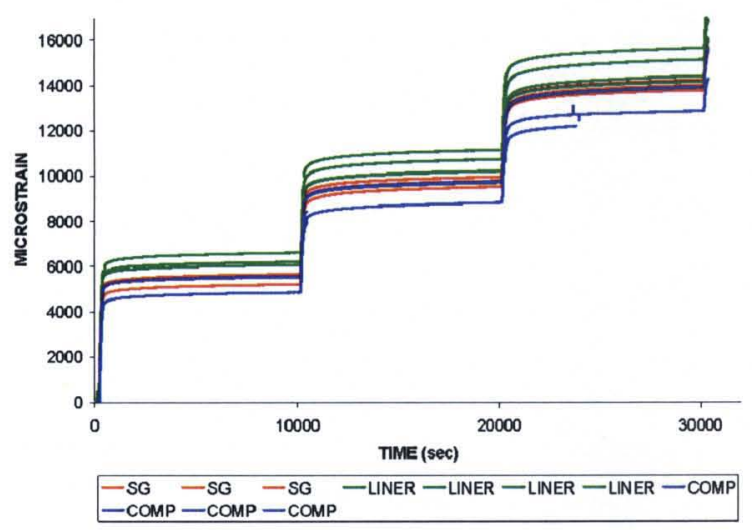

Figures 6. Figure 6 shows the combine strain data from the SSM test.

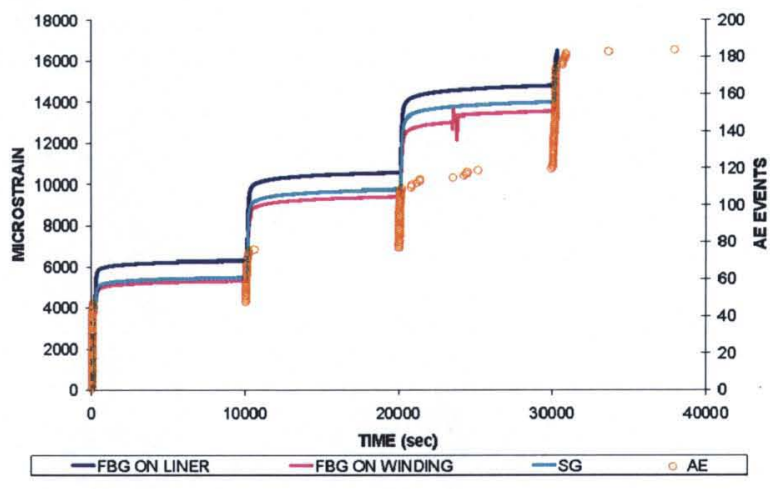

Figures 7. Figure shows the average strain data from the SSM test.

Second 6.3-Inch COPV SSM Test

On the second of the larger liners, one FBG sensor was bonded to the liner and released from the composite and one was released from the liner and exposed to the composite, where it presumably would bond to the Kevlar prepreg during elevated temperature cure. This embedded fiber only had two sensors since it was decided to sever the fiber and isolate a single sensor (of three) to apply to the outside surface of the COPV after postcuring the Kevlar prepreg. These fibers were delivered with optical connectors on each end of the fiber, making such a separation of sensors possible. All of the FBGs initially delivered from MSFC were made by Micron Optics and had peaks at 1530, 1540 and $1550 \mathrm{~nm}$. One additional FBG was delivered just prior to this test that had a single sensor with a peak wavelength (unstrained) of $1562 \mathrm{~nm}$. Pressure levels for this test were nominally 35, 55, 65 and 85 percent of burst strength $(1585,1930,2067$ and 2423 psig, respectively). Due to attenuation of some FBG signals, the pressure was reduced during the second dwell to 1140 psig in an attempt to reacquire peaks as a diagnostic check. 
Figure 8 shows the averaged microstrains for the FBGs and the strain gages. As seen in previous stress rupture tests, the axial strain gages (and in this case the FBG) exhibited significantly lower strains than for those mounted in the hoop direction.

The FBG released from the liner and exposed to the intentional bonding to the composite failed to be detected early in the test. It is quite possible that the uncontrolled surface of the overwrapped composite created a condition of multiaxial stresses that caused rapid attenuation of the peak signal. This condition was observed on the surface of the composite and attempts were made to provide a flat, pre-cured platform of epoxy to bond the sensor to minimize axial compressive stresses and to maximize uniaxial longitudinal stress on the fibers.

Figure 9 shows the fail vessel after stress rupture.

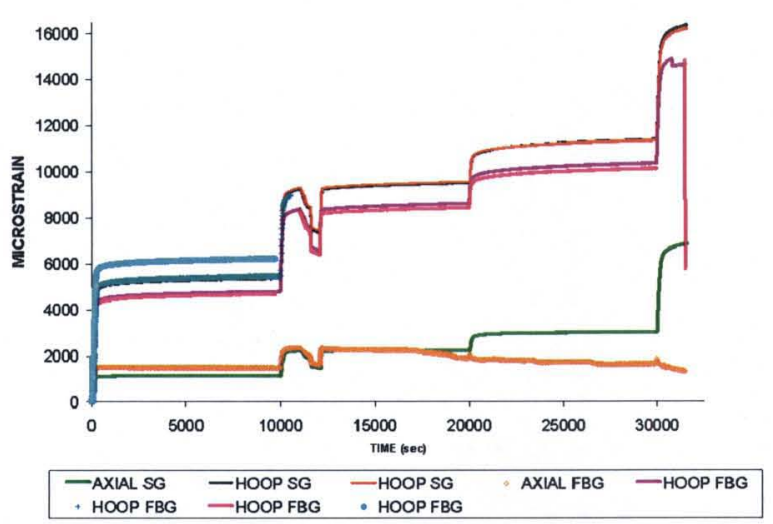

Figure 8 - Micro-strain Data

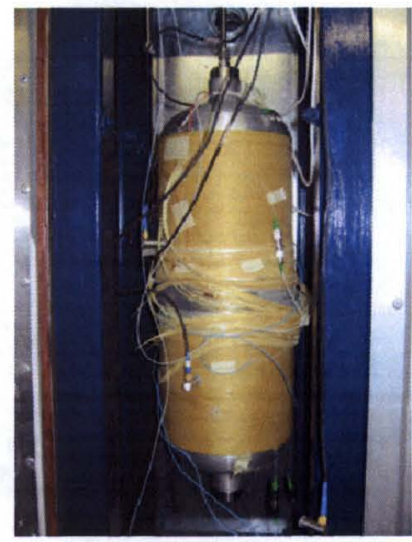

Figure 9 - failed vessel 6.3 inch COPV

\section{FBG Testing on 4.2-inch Diameter COPV}

A small liner provided by TRI was overwrapped with FBGs (three sensors, 1530, 1540 and $1550 \mathrm{~nm}$ ) bonded to the liner and also to the outer surface (single, isolated $1550 \mathrm{~nm}$ ) of the Kevlar composite (same ATK prepreg as used on the larger bottles). A standard strain gage was applied to the outer surface adjacent to the FBG. Instead of a stepped stress test, pressure was applied and removed in steps up to nearly 3000 psig as a means of comparing FBG and standard strain gages. Figure 10 shows the microstrain and pressure data recorded.

As was observed on the 6.3-inch bottles, the surface mounted FBG recorded a lower strain than the FBG bonded to the liner. However, in those tests the strain gage output better matched the surface mounted FBGs to which they were mounted adjacently. We are unaware of the cause for the lack of agreement in this test where the surface mounted strain gage output was similar to those mounted on the liner (until the FBGs signals attenuated too much to read) and remained proportionately higher than its adjacent FBG throughout the test.

Spectral data was collected prior to and at each level of high and low pressure. These are shown in the figure below. As seen in other tests, the surface mounted sensor did not 
attenuate as pressure was increased in the bottle, but the liner-mounted sensors did, to the point of total loss of peak detection due to compressive stress on the fiber. This is probably a combination of factors, one of which could be microbending and light loss in the fiber. This small liner was not polished. It appeared to the naked eye that the smaller liners had a smoother surface than the larger ones but they were not as smooth as the reclaimed, polished liners. (No surface finishes were actually measured. But should any other FBG fibers be bonded directly to liners in future testing, it is recommended that the liners be polished beforehand.

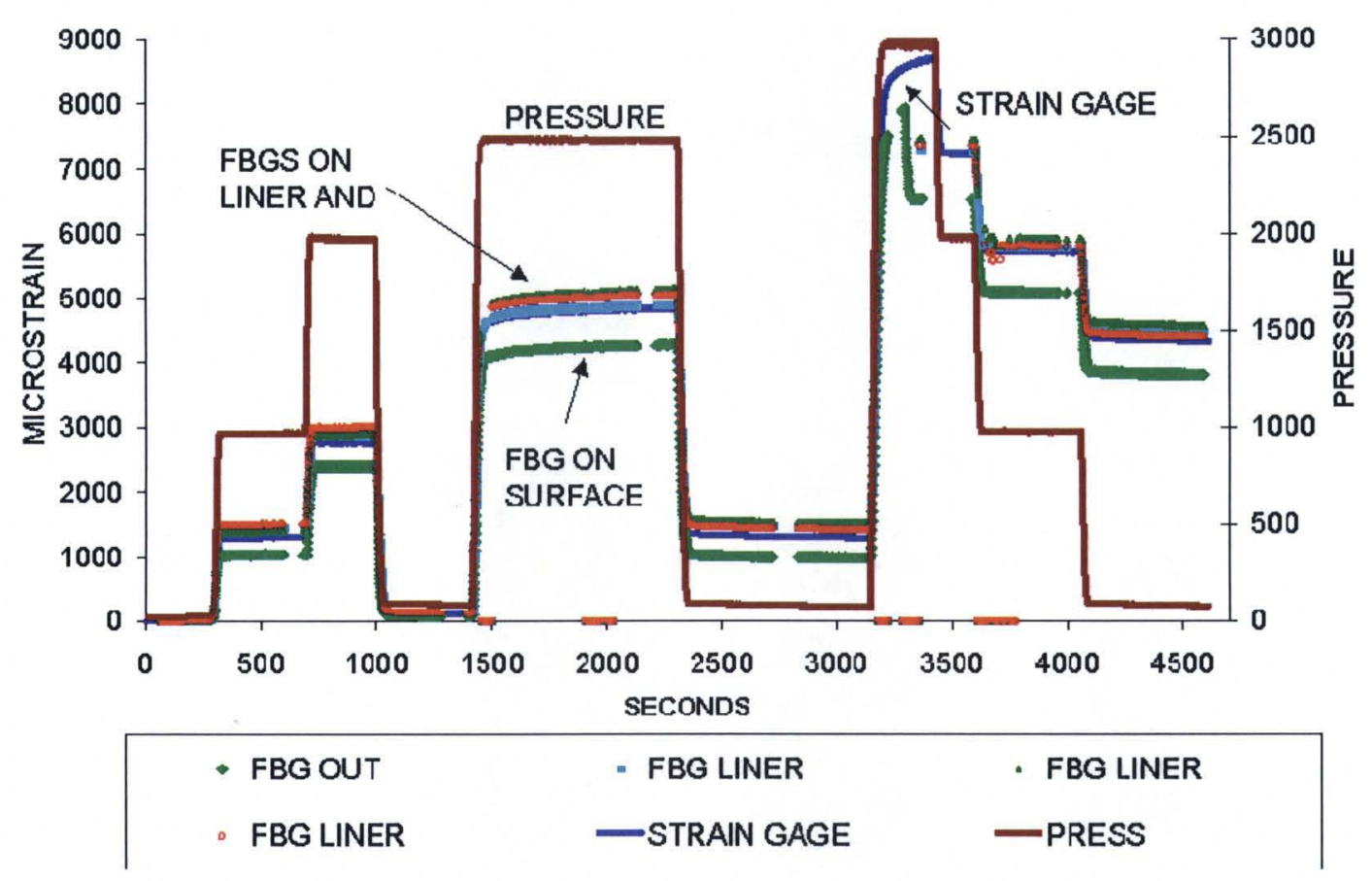

Figure 10 - Microstrain and Pressure Data from Testing of a 4.2-inch Diameter COPV

\section{Conclusion}

In conclusion we have performed stress rupture testing of COPV with embedded fiber bragg gratings. The stress fields were measured on the Kevlar overwrap and between the liner and the overwrap. The stress fields were highest between the wrap and liner.

The compressive forces during the testing caused significant attenuation as the pressure neared 3000 psi. Low bend resistance fiber optic could decrese this effect. Also, polarization maintaining fibers maybe best suited to isolate the transit and radial strain fields.

\section{References}

1. J. Grant, C. Banks, "Strain Measurements Using FBGs on Composite Overwrapped Pressure Vessels (COPV) in Stress Rupture Test", Proc. of SPIE sensor System and Networks: Phenomena, Technology, and Applications for NDE 
and Health Monitoring, San Deigo, CA, vol. 6530, pp. 653011-1-653011-10, 2007.

2. J. Derieck, W. De Waele, P. Verleysen, " Monitering of fibre reinforced composites with embedded optical fibre Bragg sensors, with application to filament wound pressure vessels" NDT\&E International 34 (2001). pp 289-296.

3. G. Kister, D. Winter, R.A. Badcock, Y.M. Gebremichael, W.J.O. Byle, B.T. Meggitt, K.T.V. Grattan, G.F. Fernando, "Structure health monitoring of a composite bridge using Bragg grating sensors. Part 1: Evaluation of Adhesives and protection systems for the optical sensors" Engineering Structuring 29 (2007) $440-448$.

4. K. Chua, P. Qiao, W.Lestari, R.J. Black, and B. Moslehi, "High-speed, High" resolution fiber Bragg grating monoring system" Proc. of SPIE sensor System and Networks: Phenomena, Technology, and Applications for NDE and Health Monitoring, San Deigo, CA, vol. 6530, pp. 65301Q-1--65301QN -12, 2007 